\title{
Trisomy 9p. A brief clinical, diagnostic and therapeutic description
}

\author{
Prof. Francisco Cammarata-Scalisi ${ }^{a}$
}

\begin{abstract}
Trisomy $9 p$ is characterized by the partial or complete duplication of the short arm of chromosome 9. It is one of the most common autosomal structural abnormalities in newborn infants. This is a relatively poor gene region, so it may be more compatible with survival. It is characterized by delayed mental and psychomotor growth, craniofacial dysmorphisms, skeletal alterations, central nervous system abnormalities, congenital heart disease, and, to a lesser extent, kidney disorders. To establish a diagnosis, it is necessary to perform a cytogenetic study with $G$ bands and, if available, fluorescence in situ hybridization complemented with comparative genomic hybridization for a better understanding of the genotype-phenotype correlation. Assessment should be interdisciplinary and encompassing a timely family genetic counseling, together with available therapeutic options in an early manner. Key words: trisomy 9p, diagnosis, genetic counseling, treatment.
\end{abstract}

http:/ / dx.doi.org/10.5546/ aap.2019.eng.e473

To cite: Cammarata-Scalisi F. Trisomy 9p. A brief clinical, diagnostic and therapeutic description. Arch Argent Pediatr 2019;117(5):e473-e476.

\section{INTRODUCTION}

Trisomy of the short arm of

a. Unit of Medical

Genetics,

Department of

Pediatrics, School

of Medicine of

Universidad de

Los Andes, Mérida,

Venezuela.

E-mail address:

Prof. Francisco

Cammarata-Scalisi:

francocammarata19@

gmail.com

Funding:

None.

Conflict of interest:

None.

Received: 9-11-2018

Accepted: 3-25-2019 chromosome $9(9 p)$ is one of the most common autosomal structural abnormalities in newborn infants. ${ }^{1}$ A potential explanation may be that this is a relatively poor gene region, so it may be more compatible with survival. ${ }^{1-3}$ Trisomy $9 p$ accounts for the fourth most frequent autosomal trisomy, after trisomies 21, 18, and $13 .{ }^{2,4}$

It was first described in 4 patients by Rethoré et al. in $1970^{1-5}$ and then outlined by Centerwall and BeattyDeSana in $1975 .{ }^{4}$ It is a clinically recognizable entity and, to date, more than 200 cases have been reported in the bibliography. ${ }^{1-6}$ It is characterized by the complete (Figure 1) or partial duplication of $9 \mathrm{p}^{2}$

\section{CLINICAL FINDINGS}

It is marked by delayed mental and psychomotor development. Craniofacial dysmorphisms include microbrachycephaly, ${ }^{1-4,7}$ wide anterior fontanelle, ${ }^{2,7}$ down and upward slant of palpebral fissures, ${ }^{1-3,7}$ hypertelorism, ${ }^{1,2,3,8}$ prominent nasal root, bulbous nose tip, $, 1,3,7,9$ short philtrum, ${ }^{3}$ down-turned corners of mouth, ${ }^{1,7-9}$ micrognathia, ${ }^{2,7}$ low-set ears, ${ }^{1,3}$ and malformed, protruding ears. ${ }^{2,9}$ The neck may be short and webbed, ${ }^{3}$ and kyphoscoliosis, lordosis,,$^{2,6}$ short stature ${ }^{3-5}$ are evidenced in the pre- or postnatal period, ${ }^{5}$ in association with delayed bone age. ${ }^{1,2,5}$ Also, limb abnormalities characterized by short fingers, ${ }^{1,10}$ clinodactyly of the fifth finger, ${ }^{9}$ and hypoplastictoe nails ${ }^{1}$ are part of the characteristics. Less commonly, central nervous system abnormalities, $, 2,4,6,7$ congenital heart disease, and kidney disorders ${ }^{2,4,6,7}$ may occur. Some studies have demonstrated an association with hepatoblastoma, ${ }^{7,9,11}$ hepatocellular carcinoma, ${ }^{11,12}$ seizures, self-harming behavior ${ }^{8}$ dysphagia, ${ }^{9}$ lupus erythematosus, and the presence of keloids. ${ }^{8}$ Table $1^{1-4,6,13}$ shows potential clinical findings of trisomy $9 p$ and their respective frequency.

Central nervous system disorders must be assessed, especially in patients with epilepsy and neuronal migration alterations. ${ }^{6}$ For example, Dandy-Walker malformation, ventriculomegaly, agenesis and hypoplasia of the corpus callosum, ${ }^{14,15}$ and large cisterna magna have been described. ${ }^{14}$

In addition, growth hormone deficiency has been characterized ${ }^{2}$ and, less frequently, insulinlike growth factor-1 deficiency. ${ }^{2,16}$ 
Treatment with recombinant human growth hormone may be considered in patients with trisomy $9 p$ with short stature, while taking into account the severity of intellectual disability and the potential for social inclusion. However, additional studies are required to establish the benefits of a taller stature in this group of patients. $^{5}$

\section{ETIOLOGY}

In most cases, partial trisomy $9 p$ occurs as a result of parental reciprocal translocation between chromosome 9 and other autosome. . $^{2,3,8}$ Therefore, phenotypic heterogeneity is correlated to the variable size of the duplicated segment (producing trisomy 9p) and the monosomy of the other chromosomal segment. ${ }^{3,4,8}$ To a lower extent, it is the result of a spontaneous (de novo) genetic alteration occurring for unknown reasons during early embryonic development, i.e., it is not passed by any of the parents. ${ }^{2,8}$

Based on the aforementioned information, establishing the genotype-phenotype correlation may be hindered by the presence of small deletions or duplications affecting other chromosomes in most reported cases of trisomy $9 p .^{2,10}$ Such additional genetic alterations make it difficult to understand which abnormalities have been caused by trisomy $9 p$ or by other chromosomal changes. ${ }^{10}$ In some cases, an additional segment in the long arm of chromosome 9 may also be present. ${ }^{2}$

However, clinical severity is related to the size of the duplicated segment of $9 p .^{3,4}$ Studies on the genotype-phenotype correlation in cases of partial trisomy $9 p$ suggested that the critical region for the phenotype was in 9p22 $\rightarrow$ p24, whereas Christ

FIGURE 1. Cytogenetic study with $G$ bands in a female patient with complete duplication of $9 p$, as shown by the arrow

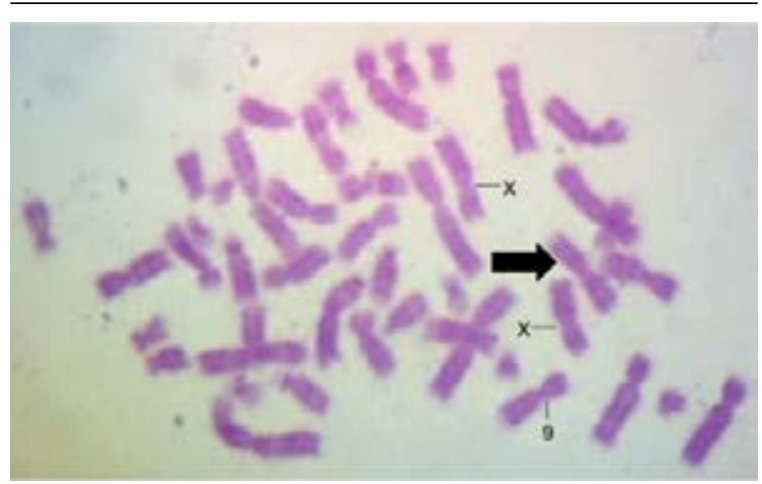

et al. proposed a shorter region located in 9p22.1

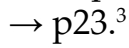

On its side, trisomy 9pter-p11 is associated with typical craniofacial characteristics, ${ }^{3}$ whereas trisomy 9p21.1-q22-32 is related to more severe craniofacial characteristics. ${ }^{2}$ Trisomy 9 pter $\rightarrow$ q11-13 presents with skeletal and heart defects, in addition to craniofacial characteristics. ${ }^{3}$ Facial clefts are uncommon, and the specific regions associated with this finding have not been clearly identified. ${ }^{10}$

TABLE 1. Clinical findings of trisomy $9 p$ and their frequency (as a percentage $)^{1-4,6,13}$

\begin{tabular}{|c|c|}
\hline Finding & Frequency $(\%)$ \\
\hline Short stature & 99 \\
\hline Delayed bone age & 99 \\
\hline Bulbous nose tip & 95 \\
\hline Down-turned corners of mouth & 95 \\
\hline Brachydactyly & 90 \\
\hline Clinodactyly & 90 \\
\hline Branchymesophalangy & 90 \\
\hline Language disorder & 90 \\
\hline Single palmar crease & $80-95$ \\
\hline Delayed puberty & $70-90$ \\
\hline Strabismus & $70-80$ \\
\hline Short philtrum & $70-80$ \\
\hline Hypertelorism & $70-80$ \\
\hline Malformed, low-set ears & $70-80$ \\
\hline Microbrachycephaly & $70-75$ \\
\hline Hypoplasia of phalanges & $70-75$ \\
\hline Hypoplastic nails & $70-75$ \\
\hline Enophthalmos & $60-70$ \\
\hline Down and upward slant of palpebral fissures & $60-70$ \\
\hline Gothic palate & $60-70$ \\
\hline Short, webbed neck & $60-70$ \\
\hline Hypotonia & $60-70$ \\
\hline Low birth weight & $50-70$ \\
\hline Kyphoscoliosis & 60 \\
\hline Lordosis & 60 \\
\hline Mental retardation & 60 \\
\hline Hip luxation & $30-40$ \\
\hline Cerebral hypoplasia & $<30$ \\
\hline Cerebellar hypoplasia & $<30$ \\
\hline Ventriculomegaly & $<30$ \\
\hline Agenesis and hypoplasia of the corpus callosum & $\operatorname{m}<30$ \\
\hline Choroid plexus cysts & $<30$ \\
\hline Epilepsy & $<30$ \\
\hline Congenital heart disease & 25 \\
\hline Ventricular septal defect & 25 \\
\hline Ebstein's anomaly & $10-20$ \\
\hline Patent ductusarteriosus & $10-20$ \\
\hline Cleft lip and palate & 5 \\
\hline Epicanthal folds & NS \\
\hline Thin upper lip & NS \\
\hline Microretrognathia & NS \\
\hline Micropenis & NS \\
\hline Kidney malformation & Infrequent \\
\hline Umbilical hernia & Infrequent \\
\hline
\end{tabular}


It has been suggested that the dosage effects of the genes located in 9pter-q22 contribute to the etiology of the already commented Dandy-Walker malformation..$^{15}$ Therefore, the genetic dosage effects, together with environmental influences, may be responsible for several abnormalities present in the central nervous system observed in this entity. ${ }^{14}$

\section{DIAGNOSIS, MANAGEMENT AND TREATMENT}

Diagnostic guidance should be aimed at confirming the existence of chromosome disease, initially through a cytogenetic study with $\mathrm{G}$ bands and, if available, with a fluorescence in situ hybridization ${ }^{6}$ complemented with comparative genomic hybridization, which is a more accurate method to measure changes in the number of copies across the genome. This method is useful to determine the region of chromosome 9 and its size, as well as other chromosomes involved, thus facilitating a more comprehensive understanding of genotype-phenotype correlations. ${ }^{10,17}$ In the presence of a structural chromosomal abnormality, these studies should be done in both patients and their parents to identify the source of the translocation, thus warranting an adequate genetic counseling. If one of the parents carries the abnormality, the risk for recurrence ranges from $2 \%$ to $15 \%{ }^{6}$
One of the basic, complementary exams that is recommended to define the phenotypic expression is a cranial (transfontanellar) ultrasound and, in the presence of an abnormality or signs suggestive of a structural abnormality, such as seizures, a brain magnetic resonance imaging should be done. For the management of seizures, the most adequate drug for this type of crises should be indicated. In addition, psychomotor development should be monitored by an interdisciplinary team, including a pediatric neurologist, a physical therapist, and different health care providers from the early care team, such as a speech therapist and an educational psychologist, among others. For treatment, it is critical to conduct interventions in relation to delayed psychomotor development through early stimulation, which should be started as early as possible. On their part, parents' involvement in stimulation is decisive to obtain the best outcomes. ${ }^{6}$

Likewise, the Departments of Ophthalmology, Cardiology, Endocrinology, Nephrology, Traumatology and Orthopedics, and Radiology should perform assessments for the presence of hypoplasia of phalanges, among other signs, while the Departments of Oncology, Medical Genetics, and Pediatrics should provide followup, as shown in Figure 2. Prognosis is highly variable depending on the severity of delayed

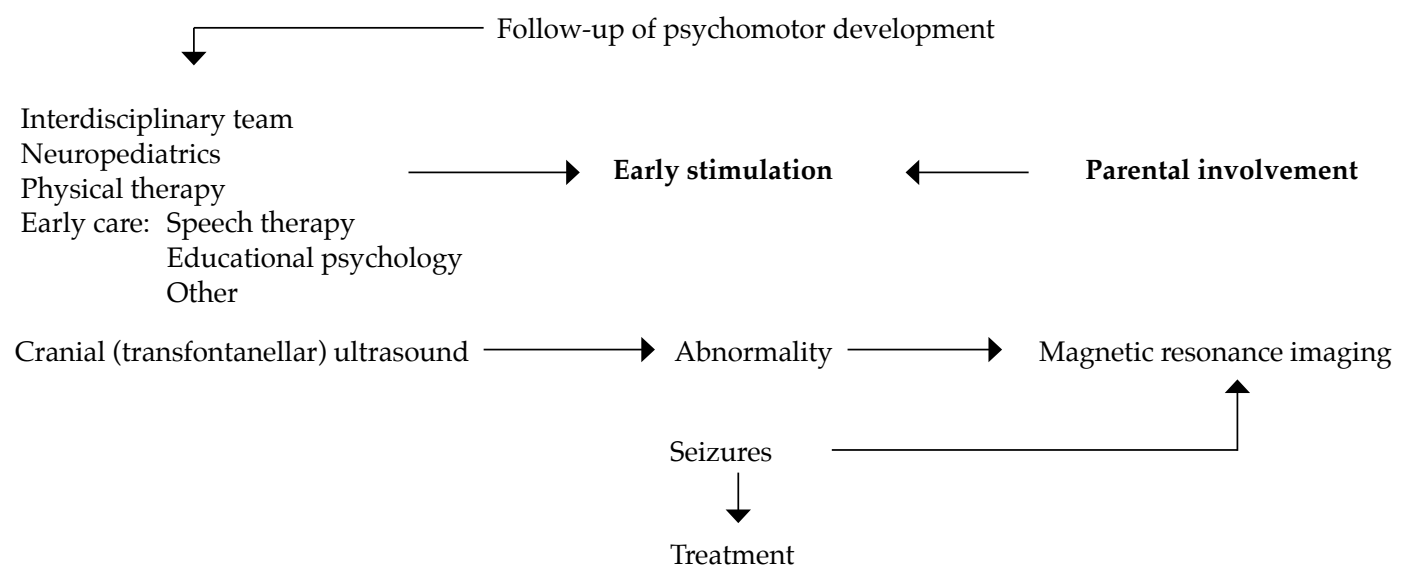

Complementary assessments: medical or surgical treatment

Ophthalmology

Endocrinology: thyroid panel, growth hormone

Traumatology and Orthopedics

Oncology: follow-up
Cardiology: electrocardiogram and echocardiogram Nephrology: kidney ultrasound Radiology: hand X-ray, abdominal ultrasound Medical Genetics: genetic counseling 
psychomotor development and the presence of seizures or heart disease, which are the most determining factors. ${ }^{6}$

\section{CONCLUSIONS}

Trisomy 9p, also known as Rethore syndrome, is a recognizable clinical entity, and the craniofacial findings of this abnormality may determine its diagnosis. ${ }^{2,18}$ This is due to the complete or partial duplication of $9 \mathrm{p} .{ }^{6}$ It is a relatively infrequent entity compatible with life. ${ }^{5}$ However, language, swallowing, pulmonary, and nutritional alterations may affect patients' quality of life. ${ }^{9}$ Phenotypic variability seems to depend on the magnitude of the genetic imbalance in each case. ${ }^{5}$

Finally, few references have been made in relation to differential diagnoses, which may be intricate due to the wide variety of clinical features. In this case, it is necessary to rule out other chromosomal entities, such as Turner syndrome, or genetic entities, like Smith-Magenis syndrome, which may present with coexisting alterations in growth, psychomotor development, intelligence quotient, language, as well as dysmorphisms, skeletal disorders, and various organ involvement.

The objective of this review is to guide clinical and cytogenetic diagnosis with available conventional or molecular methods in order to provide a timely family genetic counseling, together with available therapeutic options in an early manner. ${ }^{6}$

\section{REFERENCES}

1. Bouhjar IB, Hannachi H, Zerelli SM, Labalme A, et al. Array-CGH study of partial trisomy $9 \mathrm{p}$ without mental retardation. Am J Med Genet A. 2011; 155A(7):1735-9.

2. Stagi S, Lapi E, Seminara S, Guarducci S, et al. Long-term auxological and endocrinological evaluation of patients with 9p trisomy: a focus on the growth hormone-insulinlike growth factor-I axis. BMC Endocr Disord. 2014; 14:3.

3. Guilherme RS, Meloni VA, Pérez AB, Pilla AL, et al. Duplication $9 \mathrm{p}$ and their implication to phenotype. BMC Med Genet. 2014; 15:142.
4. Brambila-Tapia AJ,Neira VA, Vásquez-Velásquez AI,JiménezArredondo RE, et al. Pure 9p trisomy derived from a terminal balanced unreciprocal translocation. Genet Couns. 2014; 25(3):289-97.

5. Canton AP, Nishi MY, Furuya TK, Roela RA, et al. Good response to long-term therapy with growth hormone in a patient with 9p trisomy syndrome: A case report and review of the literature. Am J Med Genet A. 2016; 170A(4):1046-9.

6. San Román Muñoz M, Herranz Fernández JL, Tejerina Puente A, Arteaga Manjón-Cabeza R, et al. Trisomy 9p. An Pediatr (Barc). 2004; 61(4):336-9.

7. Martín-DeSaro MD, Valdés-Miranda JM, Plaza-Benhumea L, Pérez-Cabrera A, et al. Characterization of a complex chromosomal rearrangement involving a denovo duplication of $9 \mathrm{p}$ and $9 \mathrm{q}$ and a deletion of $9 \mathrm{q}$. Cytogenet Genome Res. 2015; 147(2-3):124-9.

8. Feng A, Dai X, Wang X, Gao Y, et al. Molecular genetic analysis of partial $9 p$ trisomy in two Chinese families with mental retardation and facial anomaly. J Huazhong Univ Sci Technolog Med Sci. 2011; 31(4):570.

9. RossiNF, Gatto AR, ColaPC, SouzaDH, etal.Oropharyngeal dysphagia and language delay in partial trisomy $9 \mathrm{p}$ : case report. Genet Mol Res. 2009; 8(3):1133-8.

10. Jelin A, Perry H, Hogue J, Oberoi S, et al. Clefting in trisomy 9p patients: genotype-phenotype correlation using microarray comparative genomichybridization.JCraniofac Surg. 2010; 21(5):1376-9.

11. SchnaterJM,Schouten-vanMeeteren AY,Heins YM, Aronson DC. Hepatoblastoma in a patient with a partial trisomy $9 p$ syndrome: a case report. Cancer Genet Cytogenet. 2005; 156(1):77-9.

12. Kitay-Cohen Y, Amiel A, Ashur Y, Fejgin MD, et al. Analysis of chromosomal aberrations in largehepatocellular carcinomas by comparative genomichybridization. Cancer Genet Cytogenet. 2001; 131(1):60-4.

13. De Pater JM, Ippel PF, Van Dam WM, Loneus WH, et al. Characterization of partial trisomy $9 p$ due to insertional translocation by chromosomal (micro)FISH. Clin Genet. 2002; 62(6):482-7.

14. Samanta D, Ramakrishnaiah R. Novel brain magnetic resonance imaging finding in a patient with trisomy $9 p$ syndrome. Acta Neurol Belg. 2015; 115(3):431-2.

15. Temtamy SA, Kamel AK, Ismail S, Helmy NA, et al. Phenotypic and cytogenetic spectrum of $9 p$ trisomy. Genet Couns. 2007; 18(1):29-48.

16. Amasdl S, Natiq A, Elalaoui SC, Sbiti A, et al. Insulin-like growth factor type 1 deficiency in a Moroccan patient with de novo inverted duplication 9p24p12 and developmental delay: a case report. J Med Case Rep. 2016; 10(1):122.

17. Al Achkar W, Wafa A, Moassass F, Liehr T. Partial trisomy 9p22 to 9p24.2 in combination with partial monosomy 9pter in a Syrian girl. Mol Cytogenet. 2010; 3:18.

18. Concolino D, Cinti R, Moricca M, Andria G, et al. Centric fission of chromosome 9 in a boy with trisomy $9 p$. Am J Med Genet. 1998; 79(1):35-7. 